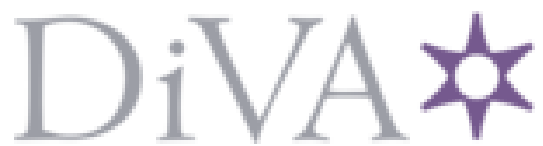

http://www.diva-portal.org

This is the published version of a paper published in International Criminal Justice Review.

Citation for the original published paper (version of record):

Ceccato, V., Solymosi, R., Müller, O. (2021)

The Use of Twitter by Police Officers in Urban and Rural Contexts in Sweden

International Criminal Justice Review, 31(4): 456-476

https://doi.org/10.1177/10575677211041926

Access to the published version may require subscription.

N.B. When citing this work, cite the original published paper.

Permanent link to this version:

http://urn.kb.se/resolve?urn=urn:nbn:se:kth:diva-305093 


\title{
The Use of Twitter by Police Officers in Urban and Rural Contexts in Sweden
}

International Criminal Justice Review $|-2|$

(C) 2021 Georgia State University (c) (i)

Article reuse guidelines: sagepub.com/journals-permissions DOI: $10.1177 / 10575677211041926$ journals.sagepub.com/home/icj

@SAGE

\author{
Vania Ceccato' (D), Reka Solymosi ${ }^{2}$, and \\ Oskar Müller'
}

\begin{abstract}
The aim of this article is to investigate the nature of information sharing via Twitter by police officers. We examine the content of Tweets in urban and rural contexts using a sample of 20 policerelated Twitter accounts, comparing official and personal accounts active in Southern Sweden. Exploratory data analysis and in-depth content analysis of a sample of Tweets compose the underlying methodology. We find a distinct pattern of consistency in the content of the information shared via the official police accounts compared to the personal accounts, regardless of if they are from urban or rural areas. However, some urban-rural differences were observed between official and personal accounts regarding public engagement, operationalized as likes and Retweets. The study calls for a discussion of new models of police engagement using social media by a society that is increasingly shaped by the internet.
\end{abstract}

\section{Keywords}

twitter, community policing, rural areas, social media engagement, internet

\section{Introduction}

Police agencies around the world are active on social media platforms (Crump, 2011; Dai et al., 2017; Meijer \& Torenvlied, 2014; Schneider \& Altheide, 2016). Social media may assist police with operational tasks, such as criminal investigations, intelligence, and crowd control. It offers a platform for communication, where police engage and interact with the general public (Dekker et al., 2020). Social media also offers a platform for individual police officers to engage with diverse audiences at an unprecedented scale.

\footnotetext{
I Department of Urban Planning and Environment, KTH Royal Institute of Technology, Stockholm, Sweden

${ }^{2}$ School of Social Science, University of Manchester, Manchester, UK

\section{Corresponding Author:}

Vania Ceccato, Department of Urban Planning and Environment, KTH Royal Institute of Technology, Teknikringen 10 A, 100 44 Stockholm, Sweden.

Email: vania.ceccato@abe.kth.se
} 
Communication via social media platforms such as Facebook and Twitter have also become much more than a source of information for the public (Dai et al., 2017). When engaging with such communication channels, individuals, and organizations alike present particular impressions of themselves. Through content posted on social media platforms, they build "exhibitions" of themselves, and their audiences interpret and engage with these impressions (Hogan, 2010), which affect public perception of the police. This is true both at the organizational level, and for individuals who publicly identify themselves as part of the police organization. Content from official, organizational accounts is seen to provide a source to verify the legitimacy of information, and even a source of emotional comfort (Bosco, 2007; Helsloot \& Ruitenberg, 2004; Jasper, 1998; Shklovski et al., 2010). And off-duty Tweeting from personal accounts helps an officer better delineate the individual from the institution, a strategy that "diminishes the appearance of authoritarian relations traditionally associated with police" (Schneider \& Altheide, 2016, p. 129), which is fundamental for police legitimacy in community policing frameworks (Grimmelikhuijsen \& Meijer, 2015).

The process by which members of the public make sense of information around them relating to crime is termed as "crime talk" (Scott et al., 2012). As we spend more and more of our lives online, "crime talk" has shifted to these spaces, including social media platforms. Therefore, as people make use of these exhibitions to engage in crime talk, and to form their impressions of the police, it is vital that we understand how police present themselves on social media platforms, and how the public engages with these exhibitions. Of special interest is how these exhibitions may differ between urban and rural contexts.

Internationally, those living in rural areas use the internet less than their urban counterparts (Berner et al., 2015), but in Sweden, the pattern of internet use is more complex. For example, the use of social media is evenly distributed between urban $(84 \%)$ and rural $(80 \%)$ areas but there are differences in platform use by age and gender. For instance, Twitter has mostly male, urban users and a majority is in the younger age group 16-25 years (Internetstiftelsen, 2019). Note that the proportion of the population aged 65 and older is significantly higher in rural municipalities (SCB - Statistics Sweden, 2021), which may indicate differences in the barriers to internet use. Therefore, a focus on rural areas is important because:

(a) these areas are often taken for granted as free-of-crime places (Yarwood \& Gardner, 2000);

(b) the physical presence of the police force is not always a guarantee to those living in rural areas (Stassen \& Ceccato, 2021);

(c) social media can play an important role because of the physical isolation and remoteness of certain areas (Ceccato \& Dolmen, 2011); and

(d) rural areas offer a number of barriers to the use of social media, such as unequal access to digital infrastructure that exacerbates differences in socio-demographic composition (Park, 2017). For example, in Swedish rural areas, the population composition (e.g., older adults) is less likely to engage with social media (Berner et al., 2015).

The way in which the police present themselves may also differ in rural contexts, as well as the manner in which populations engage with these impressions. Therefore, the aim of this article is to investigate the nature of information sharing on Twitter by police officers and understand how their exhibitions align with official guidelines. We explore Tweets of the official police accounts in terms of content of the information shared in comparison with the personal police accounts, namely individual police officers with personal Twitter accounts identifying themselves as police officers. The official police accounts are updated by police officers as part of their duties, whereas the personal ones are updated by police officers on a sporadic, voluntary basis.

In this study, we present a systematic approach to searching, inclusion, and data extraction from Tweets made by police accounts. In the resulting sample, we explore potential differences between 
official (organizational) and individual accounts, and between urban and rural contexts. It is recommended that the impressions made by police accounts should adhere to the national Police Authority guidelines on social media use. In the first instance, we evaluate whether these guidelines are in fact being followed. We then consider the impressions created by the Tweets by classifying their content based on thematic analysis. The themes are compared between different account types (official/organizational and personal/individual, urban and rural), and consider public engagement with these Tweets (operationalized as likes and Retweets).

We focus on Sweden, which constitutes a relevant case study. No studies thus far have examined the police's use of Twitter in Sweden even though police use of social media has increased in the last decade (SPA, 2016). The current literature on social media use by public authorities will benefit from exploring this in a social welfare state such as Sweden, which is limited in the international literature. The Southern region specifically has been selected because it is the second most criminogenic after the capital of Stockholm, with 161 crimes per 100,000 inhabitants (BRA, 2020), and represents a good mix of rural and urban areas.

Therefore, our contribution is two-fold. First, we demonstrate a method for search, inclusion, and data extraction from Twitter, modelled on the PRISMA framework for systematic reviews. Second, we fill a gap in the extant literature on social media use by the police in our comparison of official and personal accounts in urban and rural contexts. We begin with a literature overview on social media use by the police and links to civil society. The current study and research questions are presented in the subsequent section, followed by the results and a discussion. The article ends by highlighting the opportunities and challenges in the use of social media by the police, with particular focus on rural areas, and conclusions and recommendations for further research.

\section{Use of Social Media by the Police: A Brief Literature Overview}

\section{Police, Policing, and Social Media}

Information sharing is thought to be an essential part of contemporary community policing (Yarwood, 2015). This is carried out by making information visible and accessible to people; sharing crime prevention information and tips to reduce crime; informing the population about the police's work to increase security and reaching out that the police want tips and witness information to solve crimes (The Police Authority, 2016). Police are increasingly using social media platforms to warn citizens about threats, encourage citizens to report problems and engage citizens in investigations (Dekker et al., 2020), and in doing so, establishing and improving communication to the public.

Within these channels of information sharing, there are different contents of information that play different roles. Jurgens and Helsloot (2018) categorize the nature of support that social media users offer in emergencies into four domains: information gathering, information dissemination, collaborative problem-solving, and coping. As far as the role of the police, this can be further simplified according to Shklovski et al. (2010) into two types: informational support, which is especially important during a crisis, and emotional support, which includes people's own need to make sense of their experiences. In particular, social media is used for collectively making sense of, and coping with, a particular traumatic event. Yet, there is evidence that the constraints of police culture have meant that social media, and Twitter in particular, has been used cautiously and as a reinforcement for existing means of communication (Crump, 2011). To understand the extent to which this is the case, we can consider how police accounts align with official guidance on social media use, and how the public reacts to different types of content that are made public via Twitter.

Further, we consider two different categories of the broader topic of "police use of social media." The first category includes official, organizational accounts. For example, @polisen_malmo is the Twitter account of the Malmö police force. In this category, the police force as a hierarchical 
organization carries out one-to-many broadcasts rather than many-to-many dialogues (Dekker et al., 2020). Meijer and Torenvlied (2014) explored the use of "central" accounts (official accounts of the police) and "decentral" personal accounts to find that most Twitter communication takes place through decentralized channels (in regard to the activity on Twitter by Dutch police officers); most likely because of the types of messages greatly differ from one source to another.

The second category is when individual police officers use social media (with personal accounts) yet clearly identify themselves as members of a police organization. The use of social media by the police can be a challenge when off duty (Goldsmith, 2015). Internationally, there have been examples of "police indiscretion" involving the inappropriate use of messages (opinions vs. facts), use of inappropriate language (e.g., from parochialism to racism and sexism), and/or disclosure of sensitive information (e.g., revelation of personal data or details of a case that could potentially compromise the course of investigations) as well as misuse of social media as evidence in criminal investigations (Patton et al., 2017).

Both categories are considered here, as they both form part of the "exhibition" of police impressions on Twitter and are both consumed by members of the public (with Twitter accounts) to inform their "crime talk." Because official accounts are updated by police officers as part of their duties, it is expected that they conform more strongly to the Police Authority guidelines on social media use than the personal accounts do.

To frame our analysis, we consider the national Police Authority guidelines on social media use established by the Swedish Police Authority. The official goal of social media use is to disseminate information and create dialogue with citizens (SPA, 2016). This medium is thought to be a complement to traditional ways of contacting the police such as telephone, email, contact forms, reception, and physical police stations. The Swedish police's social media presence follows the Police Authority's overall engagement strategy centered on the police website (www.polisen.se). The use of Twitter in particular is to spread information to several different networks and give readers the opportunity to spread the information further. The authority has internal rules and routines for their own use of social media. There are guidelines for police officers to follow when using social media, and language is highlighted as an important aspect of the recommendations, including giving consideration to people with disabilities. Interestingly, the guidelines recommend that: "police officers should as far as possible, avoid using their personal accounts on duty" (SPA, 2016, p. 10). The guidelines do not offer "a code of conduct" but recommend that users should:

(a) "Avoid value-laden words and words that may be perceived as derogatory or offensive - be objective," and

(b) "Show humility and respect, avoid irony, an employee in the police should never express himself condescendingly or have an attitude that can be perceived as offensive or superior,"

(c) "Be careful with humor, as this is something very personal that can easily be misunderstood" and

(d) "The police should not link to any other organization" and photographs should be avoided,

(e) "Photographs or pictures of minors must be approved by the guardian" (SPA, 2016, pp. 10-11).

These guidelines are intended to allow the measurement and evaluation of police presence on social media platforms over time. In this study, we use these guidelines as a basis to discuss the content of the Tweets in our sample.

\section{Inequalities in the Use of Social Media in Rural Areas}

The development of digital technology has taken place at considerable speed but in an uneven way across the globe, creating new forms of inequalities (Roberts et al., 2017). Research shows 
that those living in rural areas use the internet less than their urban counterparts (Berner et al., 2015) partially because of inequalities in internet access that are exacerbated by differences in socio-demographic composition between these areas (Park, 2017). On the one hand, this development is bound to affect rural populations' access to basic services, such as access to health care services, but also impact their opportunities to use social media. On the other hand, the use of social media by police officers in remote areas is hindered by unequal digital infrastructure and a smaller pool of followers in comparison with those located in bigger cities. In Sweden, in particular, such digital inequalities also have an age dimension since rural areas have a larger share of older adults, which are likely to exhibit lower levels of technology adoption (Berner et al., 2015). Moreover, even though the number of police officers employed in Sweden has risen by $20 \%$ since 2000, Lindström (2015) showed that the increase was concentrated to larger municipalities, while some communities even experienced a decrease, and about one-quarter of all Swedish municipalities had no permanent police staff, which makes digital services even more important.

In these more remote areas, where the physical presence of police is not always guaranteed, the roles carried out by the police, police officers and other community policing groups blur and can become a source of conflict. Uhnoo and Löfstrand (2018) found, for example, that "the more effective and publicly visible the voluntary policing bodies were, the more pressure there was on the police to defend its legitimacy" (p. 41). Note, however, that this evidence is based on voluntary policing work covered by articles from traditional media and not social media entries. Therefore, it is apt to consider how police social media presence differs in urban and rural contexts, and how public engagement with such content may vary between the two.

\section{Research Questions}

Influenced by previous international research on social media and policing, and on the Twitter platform in particular, we expect to answer and discuss the following research questions in our study:

1. To what extent do Tweets made by police accounts follow the main principles contained in the Swedish Police Authority guidelines on social media use?

2. What are the key topics about which police accounts post on Twitter? How does this differ between official and personal accounts, and between urban and rural contexts?

3. How does public engagement differ between official and personal accounts? Between urban and rural contexts?

\section{The Current Study}

\section{Study Area}

As many as $98 \%$ of Swedes have access to the internet in their households. As many as $95 \%$ also use the internet. Sweden comes in fifth place in Internet use in Europe after Iceland (the average in Europe is 56\%) (Eurostat, 2019). The use of social media is evenly distributed between urban $(84 \%)$ and rural $(80 \%)$ areas but there are differences among platforms. In Sweden, Twitter is the fourth most popular platform after Facebook, Instagram, and Snapchat. For the three major social networks Facebook, Instagram, and Snapchat, the difference in number of users between rural and urban areas is small. On the other hand, there is a much greater difference for Twitter, LinkedIn, and Flashback, where a larger proportion of users live in big cities. Twitter, LinkedIn, and Flashback have more male users in Sweden and Twitter has a majority of users in the age group 16-25 years old (Internetstiftelsen, 2019). 
Of Sweden's 10.3 million residents, about 1.3 million live in rural areas. Most people are concentrated in the south, where the most accessible rural areas are located (Figure 1a). Rural areas are more criminogenic than they were a decade ago, but urban areas still have higher crime rates for all types of crime (Ceccato \& Dolmen, 2013). After the Stockholm region, where the capital of Stockholm is located, the police region named "Region South" (Region Syd) is the second most criminogenic, with 151 crimes per 1,000 inhabitants (Figure 1b) which is the same as the national rate.

The region is mostly composed of accessible rural areas (Figure 1a) which according to Swedish National Rural Development Agency (2005) are areas 5-45 min by car from urban locations with more than 3,000 inhabitants, while those with more than 3,000 inhabitants and reachable within $5 \mathrm{~min}$ by car are regarded as urban areas. The police Region South is composed of four districts —Skåne, Kronoberg, Blekinge, and Kalmar-further composed of municipalities with a variety of population sizes. Skåne is the most urban and most populous district with 1.4 million inhabitants, followed by Kronoberg with around 402,000 inhabitants, and Kalmar and Blekinge with around 372,000 and 333,000 inhabitants, respectively. Figure $1 \mathrm{~b}$ shows the crime rates for the study area in relation to the other police regions and Sweden.

\section{Data and Method}

Data Collection. To generate a sample of Tweets for our analysis, we used a novel approach to Twitter data collection, modeled on the Preferred Reporting Items for Systematic review and Meta-Analysis protocols (PRISMA) (Moher et al., 2015). Systematic reviews are the reference standard for synthesizing evidence in many academic fields (Moher et al., 2015), and provide a comprehensive method for identifying and selecting relevant papers and extracting the necessary data from these (see, e.g., Ceccato et al., 2019; Solymosi, Buil-Gil, et al., 2020; Solymosi, Petcu, et al., 2020). By applying this to the process of identifying and selecting relevant Twitter accounts, we ensure a comprehensive list of police official and personal Twitter accounts in our study area.

Search Criteria. To identify relevant accounts, we started with the official Police Sweden website (https://polisen.se/) which lists all police-affiliated social media accounts (organizational and personal). We then established the format for accounts that represents police regions as organizations (official accounts). The denomination is standard for all the regions (the name is "Polisen [Name of region]"). The official Police Sweden website also contained a list of personal accounts of police officers who appear to Tweet in an official capacity. We also used "mention-chasing," an adapted method of "citation-chasing" (Cooper et al., 2018), where we included those accounts which were mentioned in Tweets made by the identified accounts (Figure 2).

Inclusion Criteria. To select only the accounts of interest for our study, we applied the following criteria: The account must represent or belong to a force in our study area ("Region South" [Region Syd]). For police officers' personal accounts, the individual must present him- or herself as an active, serving police officer in their biography, and use a full name or a pseudonym related to their role as police officer. We then further filtered accounts which we could classify as either urban or rural based on their profile. Finally, we removed three personal accounts which were either banned or removed from Twitter between the search and inclusion and the data extraction phases.

Data Extraction. Tweets were collected from the accounts which fit out inclusion criteria. The 3,200 most recent Tweets from each account (the maximum number permitted by the free Twitter API) were queried using the free Twitter API and the rtweet R package (Kearney, 2019). The sample consisted of 14,583 Tweets made between March 08, 2013 and January 28, 2021 (date of data 


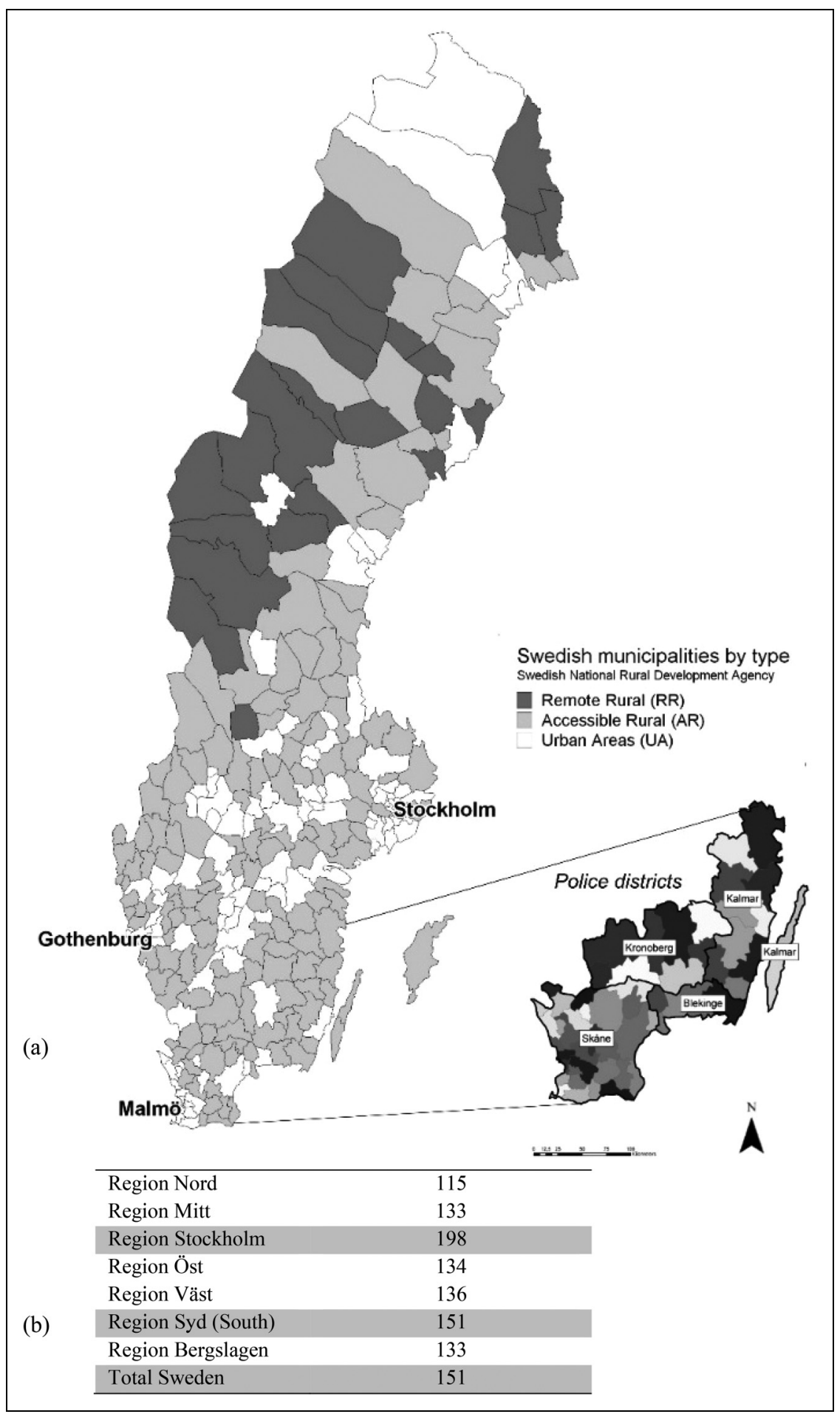

Figure I. (a) Police districts in the study area Region Syd (Skåne, Kronoberg, Blekinge, and Kalmar) and municipalities (smaller map). (b) Crimes per I,000 inhabitants by police region, 2020. Data source: BRÅ (2020) and the Swedish National Rural Development Agency (2005). 


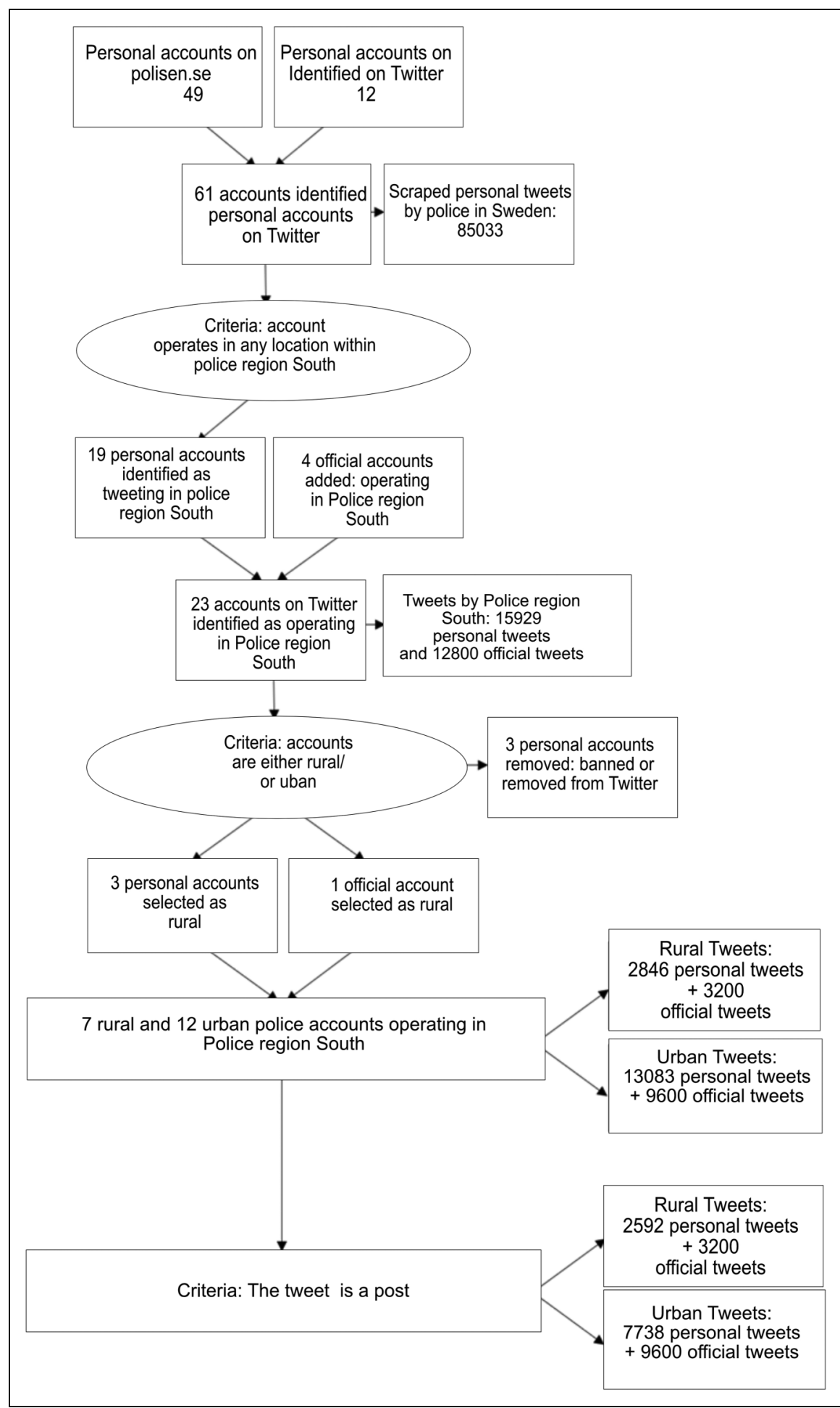

Figure 2. Selection criteria of Twitter accounts and Tweets in Region Syd (Region South): Flow activities in personal and official accounts. 
collection). We then extracted for each Tweet: the content of the message, the date and time it was made, the account which Tweeted it, the number of likes and Retweets it received to date, and coded whether it was made from an urban or rural area (Swedish National Rural Development Agency, 2008) and from an official or personal account. Finally, we kept only original content (i.e., a post) and excluded Retweets.

There is much discussion in the academic literature about whether social media data should be considered private or public (Townsend \& Wallace, 2016). Generally, if there is a reasonable expectation of privacy (Hewson \& Buchanan, 2013) such as with posts made within a closed group, the data should not be used. However, with public posts made on Twitter, there is an expectation that the content is made to be broadcast along with the opinions of others (Townsend \& Wallace, 2016). We selected only those publicly accessible, personal accounts where the person clearly identified him- or herself as an active police officer, and their social media (Twitter) profile was focused on this identity - therefore they can be understood to be representing the image of the police to the public, even if Tweeting off duty.

\section{Analytical Approach}

First, we used thematic analysis to code the content of the Tweets. Tweets were coded for the topic (e.g., Information Tweets: about how to contact the police, crime prevention programs or police warnings about traffic or special conditions, or Follow-up Tweets: that follow up on crimes, mostly about detaining criminals or questioning). Tweets were also coded for "impressions" which they make on the public - that is the tone and voice of the content produced. Coding was carried out by two of the authors (Müller and Ceccato) who discussed the emerging themes and resolved any conflicts during the coding process. Next, univariate and bivariate exploratory data analysis (Tukey, 1977) was performed to compare Tweet frequency by category, type of account, and area (urban and rural). We also included the number of Tweets made per 100 days account (Tweets per 100 days) to normalize for different lengths of active account time, that is, one expects fewer tweets from an account active for two months than one active for 2 years). See Appendix for the themes. All Tweets were in Swedish, but some example Tweets in the results have been translated to English by the authors.

\section{Results}

In total, our sample contained 14,583 Tweets from one Rural Official, four Rural Personal, three Urban Official, and 12 Urban Personal accounts. A total of 4,253 (29\%) Tweets came from official accounts, whereas 10,330 came from personal accounts (71\%); and 12,732 (87\%) Tweets came from urban accounts, whereas 1,851 (13\%) came from rural. On average, each account contained 729 Tweets (median $=504$ ), with a standard deviation of 574 Tweets (interquartile range $=886$ ), showing a lot of variation between accounts. The account with the fewest Tweets made 30 Tweets, whereas the most made 2,181 Tweets (Figure 3).

Figure 3 shows the difference in number of Tweets between official and personal accounts. Official accounts are more consistent in their Tweeting activity, whereas personal accounts have a much wider variation in Tweeting frequency.

Figure 4 shows the difference in Tweets between official and personal accounts further distinguishing between rural and urban areas. There is not a great difference between official accounts in rural and urban areas compared to the personal accounts, where urban Tweeters are more active than those in rural areas (per 100 days of account being active). In the next sections, we present the findings that answer our research questions. 


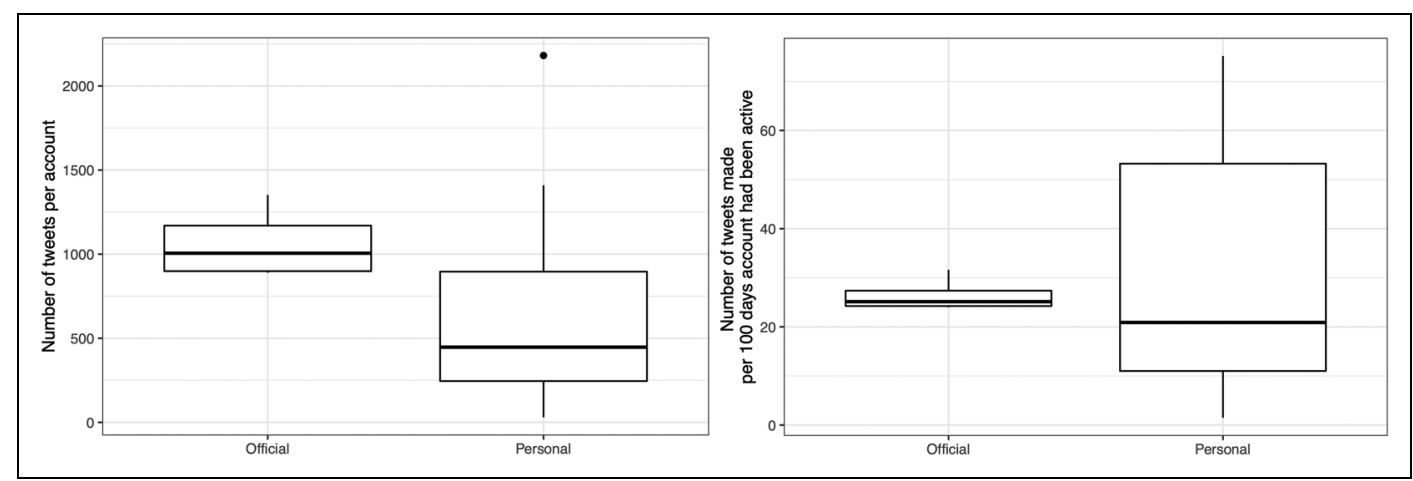

Figure 3. Difference in number of Tweets between official and personal accounts (a) Number of Tweets per account, (b) Number of Tweets made per 100 days account had been active (Tweets per 100 days is used to normalize for different lengths of active account time [i.e., one expects fewer Tweets from an account active for 2 months than one active for 2 years]).

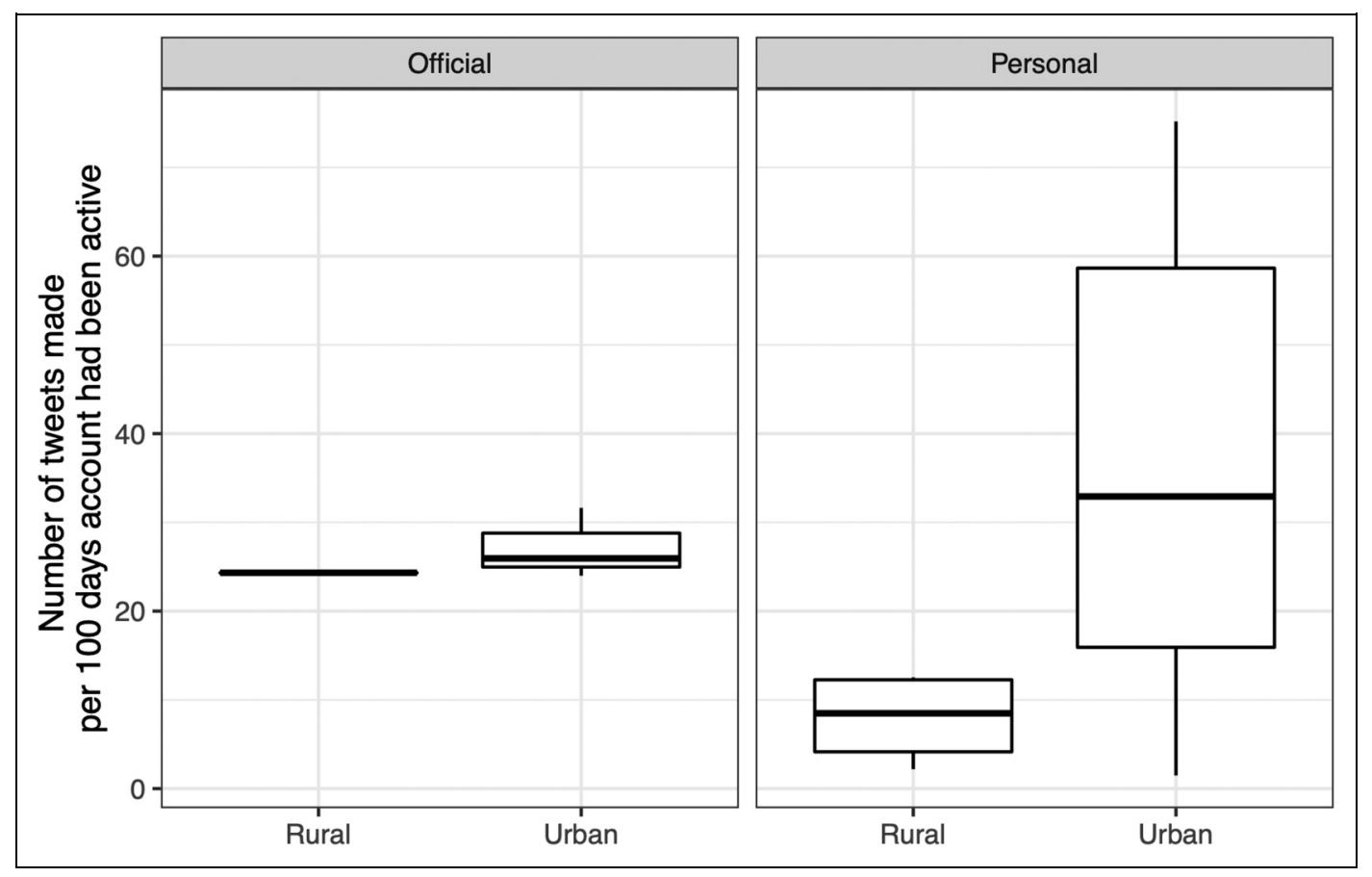

Figure 4. Number of Tweets from rural and urban accounts per 100 days of account being active.

\section{Types of Police Engagement via Social Media}

Our first research question was to what extent police social media use falls in line with official guidance, which states the main purpose is for such things as: sharing information, calling for support, warning messages, reflective of the organization, recruiting, establishing/ reinforcing cooperation with stakeholders and civil society and for putting a face on the police, humanizing the police authority, supporting each other in the organization. Coding the "impressions" made by the Tweet 
content resulted in three key themes in the Tweets which aligned with the national guidelines on social media use: Crimes, facts, and dialogue; Use of language; and Opinions, emotions, and public engagement.

\section{Themes of Tweets}

Theme 1: Crimes, facts and dialogue-Tweets from official accounts focused on a priority to reveal "the facts," such as the most common types of crime problems:

Burglary in three properties in [LOCATION] (urban, official)

Detonation at [LOCATION] police station shortly after 5. The detonation caused minor damage to the door to the property but fortunately no injuries (urban, official)

Assassination / attempted murder in [LOCATION] (rural, official)

Prosecution for very extensive poaching (rural, official)

09 January 06.35, Summary night, The night in [LOCATION] has been calm without any serious incidents or crimes (urban, official)

These Tweets simply present raw information, and do not offer any interpretation or discussion of the topics. In contrast, in personal accounts it was more common with examples of a dialogue being established between police officers and the public:

Regarding the events yesterday at [LOCATION], incitement against ethnic groups has been reported. The case will be investigated by the [NAME] Police's democracy and hate crime group. Other appropriate measures have been taken. The claim that the police were not on site is incorrect. (urban, personal)

This is how we should work against \#organizedcrime also in our local police areas (rural, personal)

Personal accounts present information in a way that shows dialogue (e.g. responding to the "crime talk" of the public by addressing an incorrect assumption) and demonstrate their perspective (using the word "should"). As suggested by Hogan (2010), with the content posted, the police officers build "exhibitions" of themselves, and their audiences interpret and engage with these impressions:

Good police work: A detainee for the murder in [LOCATION] - negotiations continue... (rural, personal)

We will work intelligence, crack down on key people, take a lot of weapons and drugs (rural, personal)

Theme 2: Use of language-All Tweets from the official accounts in our sample adhere to the national guidelines. They mostly fall within the "facts" category as presented above in the "Crimes, facts, and dialogue" theme. However, for personal accounts, despite the national guidelines, politics, and derogatory comments did appear in our sample. For example:

Never trust social democrats. They would sell their grandmother to stay in power (urban, personal)

Can look at her hair and know what she is going to write [LINK] (urban, personal) 
Despite the fact that the official guidelines suggest that "the police should not link posts to any other organization," in personal accounts it is common to find posted links between police Tweets and traditional media coverage, often as a reference and endorsement. To illustrate, these are two examples of personal Tweets by police officers about having been interviewed by radio or local TV:

I was interviewed by [USERNAME] about robbery. Check out here [LINK] (rural, personal)

SVT in [LOCATION], [NAME] was interviewed. Some dared to come forward and resist what the majority thought. Good! (rural, personal)

Theme 3: Opinions, emotions, and public engagement-Another theme, which emerged in the personal accounts, was commentary including expressed opinions and emotions about the police organization and job conditions. In these example personal Tweets, the police officers express more of "an opinion" about the current state of affairs' within police organization:

The work environment now is worse than ever in my opinion. Listen now, some colleagues in the core business are extremely tired. (urban, personal)

Leadership within the Police is very much about this. To parry sudden events, work intensively and then they take over the initiative! (urban, personal)

Gender issues within the police organization is another recurrent topic of discussion in the personal Tweets, predominantly in urban areas but also in rural areas.

Just read the Police's action plan for increased gender equality - it looks good. Maybe we can upset the male norm?! (rural, personal)

Gender equality - increases efficiency and reduces conflicts \#genderperspektiv (rural, personal)

Personal accounts also expressed a wide range of emotions, from public grief to humor and jokes, and emotion is a typical feature of the messages posted by police officers using personal accounts:

Tomorrow, Friday at $1 \mathrm{pm}$, we will have a minute of silence for our deceased blue light colleague. Firefighter died after the wire accident on E4. (rural, personal)

It is hardly possible to find words for the tragedy in today's fatal shooting. Poor family and relatives. It is not possible to understand their grief. ...Heavy. (urban, personal)

I have started recharging before the midsummer celebration on Friday. Bought herring, sour cream, strawberries, blankets, candles, winter jacket, underpants and skates... (urban, personal)

While it appears that many Tweets from personal accounts deviate from the official guidelines, we also observed that replies to such Tweets indicate that such impressions presented by the police are appreciated by individuals from the local community and vice versa. We will explore this more with quantified measures of engagement in the next sections, but first we consider what topics are Tweeted about. 


\section{Counting Tweet Topics}

Of the total Tweets, $66 \%$ were about crime events, and 34\% were Tweets about something else, such as follow-up Tweets, replies, police education, promotion of events, Tweets about the police organization and informational Tweets (Appendix).

\section{Tweets Topics by Official and Personal Accounts}

In our sample, official accounts post mostly about crimes, specifically property crimes such as burglary, car-related thefts, and robbery. Personal accounts on the other hand frequently post other types of Tweets, for example: Tweets about the police organization (as relating to policing, the structure of police work, colleagues, meetings, and so on); then violence, other crime, then follow-up Tweets commenting on particular crimes, mostly about detaining criminals, then posts of drugs and illegal substances-compose the $6^{\text {th }}$ most common posts. Examples of such follow-up Tweets include:

[@USERNAME] No. It is the actual vulnerability that is measured. It thus does not matter whether the crime is reported or not. (personal, urban)

[@USERNAME] yes ... Thanks. Colleagues, you did a fantastic job! \& (-) (personal, rural)

Figure 5 illustrates the most frequent topics for personal and official accounts:

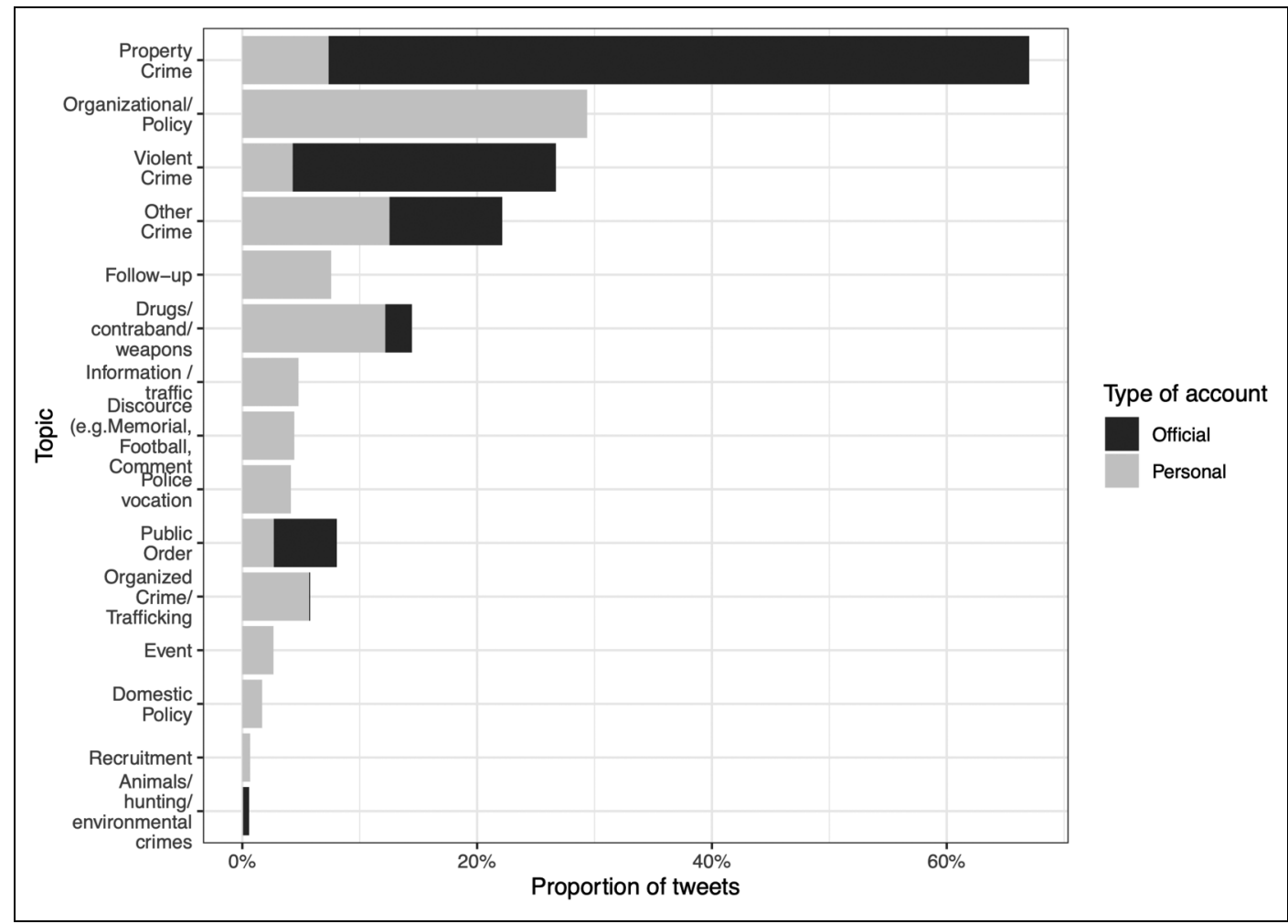

Figure 5. Most frequent topics for personal and official accounts (showing the distribution of all official [100\%] and all personal [another 100\%] together). 


\section{Tweet Topics in Rural and Urban Areas}

The proportion of crime-related Tweets is greater in rural accounts than in urban contexts. In rural areas, all crime-related Tweets encompass $76 \%$ of the total while in urban areas, this percentage falls to $64 \%$, with the remaining $36 \%$ being noncrime-related Tweets. In rural areas, crime-related Tweets are dominated by property crimes such as car-related thefts (14\%) and burglaries (14\%), then followed by assaults $(8 \%)$, organized crime $(4 \%)$, and drugs $(4 \%)$. In urban areas, burglary (7\%), robbery $(7 \%)$, car-related thefts $(6 \%)$, and follow-up Tweets compose the largest share of crime-related Tweets $(9 \%)$.

There are differences in the types of content in the urban and rural posts between official and personal accounts as well. While in rural areas, Tweets from personal accounts focus on drugs and illegal substances and organized crime, in urban personal accounts, follow-up Tweets are the most frequent. Tweets in rural contexts also vary depending on whether they come from an official or personal account. Official Tweets in rural areas show less variation in topic and deal with crimes, often property crimes such as car-related thefts, burglary, assault, robbery, and theft. Personal Tweets in general are composed of more complex messages, about a variety of subjects, from the organization of the police, organized crime, illegal drugs, follow-ups, police education, replies, weapons, and robbery to contraband.

\section{Public Engagement by Context and Account Type}

We considered engagement operationalized as likes and Retweets of each Tweet. As hinted in the section "Themes of Tweets," personal accounts in both urban and rural settings receive more engagement with their Tweets, however there is also greater variation in these measures (Figure 6a and 6b). Official accounts, on the other hand, receive consistently low engagement. The average number of likes for official police Tweets was 0.51 with a standard deviation of 1.43 . For personal Tweets, the average and standard deviation for the number of likes were 8.52 and 53.2, respectively (Figure 6).

\section{Discussion of Results}

Our study utilized a novel approach to systematically review Tweets made by police accounts in the southern region of Sweden. Based on the thematic coding and descriptive analysis of 14,583 Tweets from 20 police accounts, we explored whether (1) Tweets aligned with the main principles contained in the Swedish Police Authority guidelines on social media use and (2) the key topics covered, and how these varied between personal and official accounts in rural and urban environments, as well as (3) how public engagement, measured as likes and Retweets varied between these settings.

The Swedish Police Authority guidelines on social media use promote the use of Twitter and other platforms as part of the community policing model. The principles are general recommendations about how to produce and share information. We found that while the official accounts tend to follow the guidelines on social media use, personal accounts contravene the guidance more frequently. Some personal-account Tweets use value-laden words and words that may be perceived as derogatory or offensive.

There were some differences in the most common topics of urban and rural Tweets, in particular in relation to property and violent crimes, where official accounts Tweet more about property crimes, while personal accounts focus on noncrime, followed by violent crime, before property crime. The notable finding here is that urban areas seem to have more public engagement with more Tweets in the "follow-up" category. 


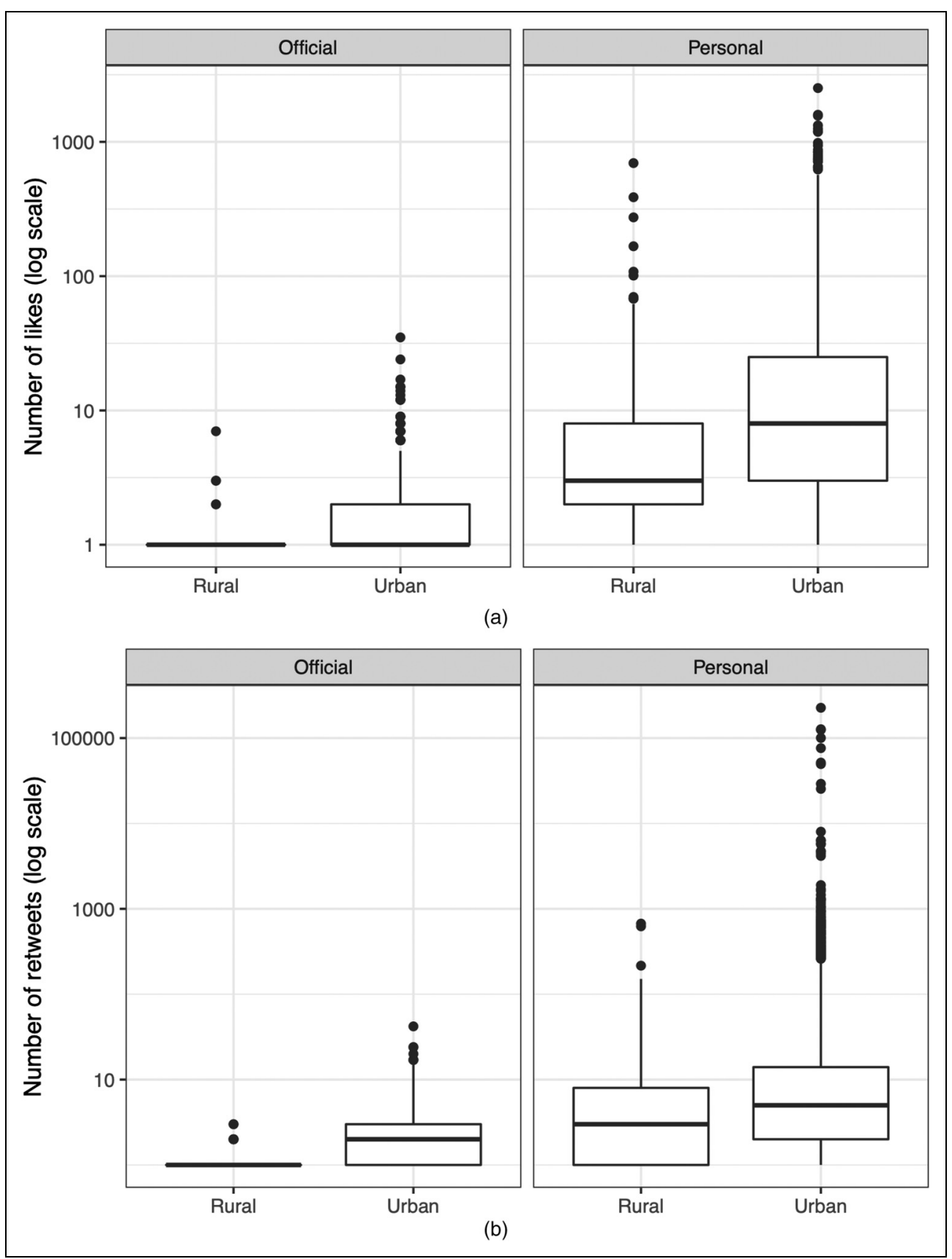

Figure 6. Likes (a) and Retweets (b) in personal and official accounts in rural and urban contexts.

We found less variation in content between urban and rural areas in the number of Tweets from official accounts. However, although official accounts are more consistent in Tweeting, they generate less engagement than the rural personal accounts, which Tweet less frequently but generate more engagement. There are indications of the presence of "enthusiasts" (eldsjälar) in rural communities who tend to attract followers and reactions, such as likes and Retweets. These active officers are the 
ones dominating the local discourse and feeding the "crime talk," and are possibly the key faces of community policing.

Fact-based Tweets dominate posts made from official police accounts, most often dealing with crime occurrence or information of public interest, which is in line with the Police Authority guidelines on social media use. However, the content of Tweets from personal accounts differs from the police authority guidelines in that it is less based on facts and more on opinions and emotions. These personal Tweets comprise follow-ups of all sorts, replies, information, but also anecdotes about crimes, opinions about daily events and politics. This may also explain why the personal accounts are more "popular" (measured by likes and Retweets) than the official ones as previously suggested by Crump (2011) in the Canadian case, where a difference between police force accounts and local team/individual officer accounts is also observed. Denef et al. (2013) also made a similar finding, where Greater Manchester Police force's social media engaged more "genuinely" with the public than the Metropolitan Police Force, and therefore was viewed more favorably by the public. In line with this, in our study, Tweets from official accounts received on average fewer likes and Retweets than those posted by police officers using personal accounts.

Previous research has shown that the presence of the police contributes to public reassurance (Stassen \& Ceccato, 2021), namely that the physical presence of police officers affects public confidence in the police as a public authority (Wakefield \& Fleming, 2009). In our study, we found limited engagement with the one rural official account, however greater engagement with the rural personal accounts. However, this rural engagement was in both cases still lower than the engagement with both types of urban accounts. In Sweden, because of the rural population's composition (e.g., older adults) and unequal access to digital infrastructure (Park, 2017), people living in rural areas are less likely to engage with social media (Berner et al., 2015) and consequently with the police. Similarly, in the Netherlands, Grimmelikhuijsen and Meijer (2015) showed that the number of citizens engaging online with the Dutch police via Twitter was small, and therefore there was no direct relationship between participation and the perceived legitimacy of the police. Future research should investigate ways to better capture the strengths of digital social networks in rural environments, especially in relation to the role of the police and emergency services.

One recommendation from our study is to consider the balance between following the Police Authority guidelines on social media use and engaging genuinely with the public. Tweets posted from official accounts seem to follow the guidance on tone so strictly, that there is no emotion in their Tweets, and the low engagement numbers (likes and Retweets) suggests that this might not be the best way to engage the public. Crump (2011) proposes some general strategies that the police force might adopt in order to maximize the effectiveness of Twitter. One model is creating a broadcaster that seeks to maximize the number of followers, especially those in their target audiences; the other model is to select a number of local knowledge gatherers who can maximize the number of people followed, especially in the local community and finally, to create community facilitators who employ elements of both strategies to encourage relatively dense groups within their networks as potential sources of comments on ideas and sharing news. In our case, it seems that engaging with the police officers' personal accounts might offer a way to achieve this, or perhaps at least bring the official accounts closer in tone to the individual accounts. However, a balance is needed, as we found examples of derogatory comments among the personal Tweets, indicating an issue where police officers are not following the principles outlined within the national guidelines in terms of when they Tweet (e.g., duty or off duty), how they Tweet (e.g., language and expression of values and emotions) or what they Tweet about (e.g., issues of privacy, disclosure).

Yet we believe that we can suggest considering the tone perceived from the way the Tweet is written, which is in line with previous work. For instance, Solymosi, Petcu, et al. (2020), found that having a clear strategy when sending Tweets (for Missing People appeals) pays off. For instance, Tweets using police custody images have lower Retweet rates than those with regular photos, and 
Tweets asking, "have you seen. . .?" with an explicit request to be Retweeted generate more Retweets. It is important to note that individuals who connect themselves with police accounts on social media are composed of a relatively heterogeneous group, differ in the way they use social media (e.g., Facebook or Twitter) and differ in terms of personality (Dai et al., 2017). Therefore any attempt to suggest one-size-fits-all solutions to social media-related issues may not be appropriate, especially in rural contexts.

As any study of this kind, this study has a number of limitations. First, Kwan (2016) calls for caution in that the knowledge attained through analyzing crowdsourced data may not reflect reality, but rather the characteristics of the algorithms involved in retrieving and processing it. While we keep this in mind, we also agree with Miller (2010) that these data limitations should not altogether discount the importance of crowdsourced data in research. Second, the study does not analyze the types of followers of these police accounts. This could provide an indication of whether or not the aim of establishing channels to the public is being met via the use of social media, in particular via Twitter. Without analysis of a larger sample of accounts of different types, it is not possible to draw conclusions based on a comparison between the rural and urban areas or attach significance to changes over time. However, as suggested by Crump (2011), Twitter is for microblogging, and supports an asymmetric form of communication, that is, official police accounts generally have much larger numbers of followers than they themselves follow. Therefore, it is difficult to conclude from this analysis alone what value users get from the information they receive through Twitter, although there are reasons to believe that communication through social media plays an important role in the process of information sharing and engagement with communities, in particular in rural contexts. For example, although Tweets from police officers' personal accounts are more sporadic (i.e., don't Tweet with such even consistency), they seem to generate more engagement than the official accounts. Finally, our analysis of public engagement makes the assumption that more likes and Retweets indicate positive engagement by the public, whereas it is possible something is retweeted in bad faith. Further research can carry out more in-depth analysis of people's perceptions and motivations to better unpack this issue. Note also, that our data includes Tweets made during the COVID-19 pandemic, which might affect Tweeting behavior (Nikolovska et al., 2020). Despite these limitations, the study is exploratory in its attempt to illustrate the potentialities and challenges of using social media (in this case, Twitter) by the police, via both official/organizational and personal/individual accounts, as an instrument of reporting incidents and/or of action in community policing beyond urban contexts, which was thus far lacking in the international literature.

\section{Conclusion}

The intention of this article was to provide an overview of how police use social media, in particular the use of Twitter in urban and rural contexts. We consider this study as exploratory in nature as the analysis is based on a sample of entries from 20 police accounts divided into official/organizational and personal/individual accounts, with the large majority being accounts from urban areas but a few from rural areas.

Although it is still unknown if the presence of police organizations and officers on social media has the same effect as their physical presence, our findings confirm previous results (Crump, 2011; Meijer \& Torenvlied, 2014) showing that information sharing may be richer than previously reported, depending on the type of account and contexts in which they are embedded. Assuming that more investments are made in this area, new ways of thinking about the role of police officers on social media is needed. In order to increase the audience and public engagement, the national Police Authority guidelines on social media use should embrace recommendations that provide a better balance between strictly informative Tweets and those that generate debate and emotional engagement.

Moreover, we call for new models of police engagement in community policing by a society that is currently being shaped by the internet, resulting in "crime talk" moving online, and presenting new 
challenges for police to present an "exhibition" to the public, which can garner favorable impressions and therefore build public trust and confidence in the police. In particular, we need to seriously take into account the threat of digital exclusion of rural populations against a background of fewer police officers being available in the most remote areas of the country.

\section{Declaration of Conflicting Interests}

The author(s) declared no potential conflicts of interest with respect to the research, authorship, and/ or publication of this article.

\section{Funding}

The author(s) received no financial support for the research, authorship, and/or publication of this article.

\section{ORCID iD}

Vania Ceccato iD https://orcid.org/0000-0001-5302-1698

\section{References}

Berner, J., Rennemark, M., Jogréus, C., Anderberg, P., Sköldunger, A., Wahlberg, M., Elmståhl, S., \& Berglund, J. (2015). Factors influencing internet usage in older adults (65 years and above) living in rural and urban Sweden. Health Informatics Journal, 21(3), 237-249. https:/doi.org/10.1177/1460458214521226

Bosco, F. J. (2007). Emotions that build networks: Geographies of human rights movements in Argentina and beyond. Journal of Economic and Social Geography, 98(5), 545-563. https://doi.org/10.1111/j.1467-9663. 2007.00425.x

BRA (2020). Reported crimes per 1000 inhabitants. https://www.regionfakta.com/skane-lan/in-english/healthand-sickness/reported-crimes-per-1000-inhabitants[A10]/.

Ceccato, V., \& Dolmen, L. (2011). Crime in rural Sweden. Applied Geography, 31(1), 119-135. https://doi.org/ 10.1016/j.apgeog.2010.03.002

Ceccato, V., \& Dolmen, L. (2013). Crime prevention in rural Sweden. European Journal of Criminology, 10, 89-112. https://doi.org/10.1177/1477370812457763

Ceccato, V., Vasquez, L., Langefors, L., Cannabarro, A., \& Petersson, R. (2019). Trygg stadsmiljö: Teori och praktik för brottsförebyggande \& trygghetsskapande åtgärder. KTH. https://www.boverket.se/globalassets/ publikationer/dokument/2019/trygg-stadsmiljo.pdf

Cooper, C., Booth, A., Varley-Campbell, J., Britten, N., \& Garside, R. (2018). Defining the process to literature searching in systematic reviews: A literature review of guidance and supporting studies. BMC Medical Research Methodology, 18(1), 85. https://doi.org/10.1186/s12874-018-0545-3

Crump, J. (2011). What are the police doing on Twitter? Social Media, the Police and the Public, 3(4), 1-27. https://doi.org/10.2202/1944-2866.1130

Dai, M., He, W., Tian, X., Giraldi, A., \& Gu, F. (2017). Working with communities on social media. Online Information Review, 41(6), 782-796. https://doi.org/10.1108/OIR-01-2016-0002

Dekker, R., van den Brink, P., \& Meijer, A. (2020). Social media adoption in the police: barriers and strategies. Government Information Quarterly, 37(2), 101441. https://doi.org/10.1016/j.giq.2019.101441

Denef, S., Bayerl, P. S., \& Kaptein, N. A. (2013). Social media and the police: tweeting practices of British police forces during the August 2011 riots. Proceedings of the SIGCHI Conference on Human Factors in Computing Systems (pp. 3471-3480). Association for Computing Machinery. https://doi.org/10.1145/ 2470654.2466477

Eurostat. (2019). Digital economy and society statistics - households and individuals. https://ec.europa.eu/ eurostat/statistics-explained/index.php?title=Digital_economy_and_society_statistics_-_households_and_ individuals 
Goldsmith, A. (2015). Disgracebook policing: Social media and the rise of police indiscretion. Policing and Society, 25(3), 249-267. https://doi.org/10.1080/10439463.2013.864653

Grimmelikhuijsen, S. G., \& Meijer, A. J. (2015). Does Twitter increase perceived police legitimacy? Public Administration Review, 75(4), 598-607. https://doi.org/10.1111/puar.12378

Helsloot, I., \& Ruitenberg, A. (2004). Citizen response to disasters: A survey of literature and some practical implications. Journal of Contingencies and Crisis Management, 12(3), 98-111. https://doi.org/10.1111/j. 0966-0879.2004.00440.x.

Hewson, C., \& Buchanan, T. (2013). Ethics guidelines for internet-mediated research.

Hogan, B. (2010). The presentation of self in the age of social media: Distinguishing performances and exhibitions online. Bulletin of Science, Technology \& Society, 30(6), 377-386. https://doi.org/10.1177/ 0270467610385893

Internetstiftelsen. (2019). Svenskarna och internet 2019. file://C:/Users/vace/Vanias\%20document/SIs/Methods \%20_SI/Twitter_Reka_Oskar/svenskarna-och-internet-2019-a4.pdf

Jasper, J. M. (1998). The emotions of protest: Affective and reactive emotions in and around social movements. Sociological Forum, 13(3), 397-424. https://doi.org/10.1023/A:1022175308081

Jurgens, M., \& Helsloot, I. (2018). The effect of social media on the dynamics of (self) resilience during disasters: A literature review. Journal of Contingencies and Crisis Management, 26(1), 79-88. https://doi.org/10. $1111 / 1468-5973.12212$

Kearney, M. W. (2019). rtweet: Collecting and analyzing Twitter data. Journal of Open Source Software, 4(42), $18-29$.

Kwan, M.-P. (2016). Algorithmic geographies: Big data, algorithmic uncertainty, and the production of geographic knowledge. Annals of the American Association of Geographers, 106(2), 274-282. https://oi.org/ $10.1080 / 00045608.2015 .1117937$

Lindström, P. (2015). Police and crime in rural and small Swedish municipalities. Journal of Rural Studies, 39, 271-277. https://doi.org/10.1016/j.jrurstud.2014.12.004

Meijer, A. J., \& Torenvlied, R. (2014). Social media and the new organization of government communications: An empirical analysis of Twitter usage by the Dutch police. The American Review of Public Administration, 46(2), 143-161. https://doi.org/10.1177/0275074014551381

Miller, H. J. (2010). The data avalanche is here. Should't be digging? Journal of Regional Science, 50(1), 181201. https://doi.org/https://doi.org/10.1111/j.1467-9787.2009.00641.x

Moher, D., Shamseer, L., Clarke, M., Ghersi, D., Liberati, A., Petticrew, M., \& Stewart, L. A. (2015). Preferred Reporting Items for Systematic Review and Meta-Analysis Protocols (PRISMA-P) 2015 statement. Systematic Reviews, 4(1), https://doi.org/10.1186/2046-4053-4-1

Nikolovska, M., Johnson, S. D., \& Ekblom, P. (2020). "Show this thread": policing, disruption and mobilisation through Twitter. An analysis of UK law enforcement tweeting practices during the Covid-19 pandemic. Crime Science, 9(1), 1-16.

Park, S. (2017). Digital inequalities in rural Australia: A double jeopardy of remoteness and social exclusion. Journal of Rural Studies, 54, 399-407. https://doi.org/10.1016/j.jrurstud.2015.12.018

Patton, D. U., Brunton, D.-W., Dixon, A., Miller, R. J., Leonard, P., \& Hackman, R. (2017). Stop and frisk online: Theorizing everyday racism in digital policing in the use of social media for identification of criminal conduct and associations. Social Media + Society, 3(3), 2056305117733344. https://doi.org/10.1177/ 2056305117733344

Roberts, E., Beel, D., Philip, L., \& Townsend, L. (2017). Rural resilience in a digital society: Editorial. Journal of Rural Studies, 54, 355-359. https://doi.org/10.1016/j.jrurstud.2017.06.010

SCB - Statistics Sweden. (2021). Sveriges framtida befolkning 2020-2030 - Län och kommungrupper. https:// scb.se/hitta-statistik/statistik-efter-amne/befolkning/befolkningsframskrivningar/befolkningsframskrivninga r/pong/publikationer/sveriges-framtida-befolkning-20202030/.

Schneider, C. J., \& Altheide, D. A. (2016). Policing and social media: Social control in an era of new media. Lexington Books. 
Scott, J., Carrington, K., \& McIntosh, A. (2012). Established-outsider relations and fear of crime in mining towns. Sociologia Ruralis, 52(2), 147-169. https://doi.org/10.1111/j.1467-9523.2011.00557.x

Shklovski, I., Burke, M., Kiesler, S., \& Kraut, R. (2010). Technology adoption and use in the aftermath of Hurricane Katrina in New Orleans. American Behavioral Scientist, 53(8), 1228-1246. https://doi.org/10. $1177 / 0002764209356252$

Solymosi, R., Buil-Gil, D., Vozmediano, L., \& Guedes, I. S. (2020). Towards a place-based measure of fear of crime: A systematic review of app-based and crowdsourcing approaches. Environment and Behavior, 0013916520947114. https://doi.org/10.1177/0013916520947114[A17]

Solymosi, R., Petcu, O., \& Wilkinson, J. (2020). Exploring public engagement with missing person appeals on Twitter. SocArXiv, January 27. https://doi.org/10.31235/osf.io/wugxs [Record \#4539 is using a reference type undefined in this output style.].

Stassen, R., \& Ceccato, V. (2021). Police accessibility in Sweden: An analysis of the spatial arrangement of police services. Policing: A Journal of Policy and Practice 15(2), 896-911, https://doi.org/10.1093/ police/paz068

Swedish National Rural Development Agency. (2005). Sveriges gles-och landsbygder 2005. Västerås: Edita Västra Aros.

Swedish National Rural Development Agency. (2008). Rural Sweden: Facts and figures.

The Police Authority. (2016). Guidance police in social media (Tutorial the police in social media, Issue), Communications Department, Version 2.4

Townsend, L., \& Wallace, C. (2016). Social media research: A guide to ethics. University of Aberdeen, 1, 16. Tukey, J. W. (1977). Exploratory data analysis (Vol. 2). Addison-Wesley.

Uhnoo, S., \& Löfstrand, C. (2018). Voluntary policing in Sweden: Media reports of contemporary forms of police-citizen partnerships. Journal of Scandinavian Studies in Criminology and Crime Prevention, 19(1), 41-60. https://doi.org/10.1080/14043858.2018.1439635

Wakefield, A., \& Fleming, J. (2009). Responsibilization. In The SAGE dictionary of policing (pp. 277-278). SAGE Publications Ltd. https://www.doi.org/10.4135/9781446269053.n111

Yarwood, R. (2015). Lost and found: The hybrid networks of rural policing, missing people and dogs. Journal of Rural Studies, 39, 278-286. https://doi.org/10.1016/j.jrurstud.2014.11.005

Yarwood, R., \& Gardner, G. (2000). Fear of crime, cultural threat and the countryside. Area, 32(4), 403-411. https://doi.org/10.1111/j.1475-4762.2000.tb00156.x

\section{Author biography}

Vania Ceccato is a Professor at KTH Royal Institute of Technology, Stockholm, Sweden. Geographical Information Systems (GIS) and spatial methods underlie her research that includes the geography of crime and fear in urban and rural environments. She wrote the open access book "Rural Crime and community safety" by Routledge and she is coordinator of Safeplaces network, a partner of UN-Habitat SaferCities program.

Dr Reka Solymosi is a Lecturer in Quantitative Methods at the Department of Criminology at University of Manchester. She is a member of the Software Sustainability Institute and an Honorary Lecturer at University College London. Her research focuses on making use of new forms of data to gain insight into people's behaviour and subjective experiences, particularly focusing on crime, victimisation, transport, and spatial research. She is dedicated to promoting data literacy in social science study and practice.

Oskar Müller is a Master student at KTH Royal Institute of Technology, Stockholm, Sweden. Topics of study include regional planning, municipal relations and Geographical Information Systems (GIS). His master thesis explores relations between rural crime prevention and regional planning. 


\section{Appendix: Thematic Coding of Tweets by Topic Category: Examples of Crime-related and Noncrime-related Tweets.}

\begin{tabular}{|c|c|}
\hline Crime-related Tweets & Noncrime-related Tweets \\
\hline $\begin{array}{l}\text { - Riots } \\
\text { - } \text { Illegal hunting } \\
\text { - } \text { Burglary } \\
\text { - } \text { Rar-related thefts } \\
\text { - } \text { Assault/threats } \\
\text { - Thefts } \\
\text { - } \text { Drugs } \\
\text { - Murder/homicide } \\
\text { - Smuggling/Trafficking } \\
\text { - Organized crime } \\
\text { - Weapons } \\
\text { - } \text { Detonation: bombs, } \\
\text { grenade } \\
\text { - Fraud } \\
\text { - Vandalism } \\
\text { - Social disturbance } \\
\text { - Sexual crime } \\
\text { - Hate crime } \\
\text { - } \text { Sabotage } \\
\text { Forgery }\end{array}$ & $\begin{array}{l}\text { - Information Tweets-are about how to contact police, crime prevention } \\
\text { programs or police warnings about traffic or special conditions (e.g., Today was } \\
\text { the kick-off for the largest crime prevention effort we have made so far in } \\
\text { NW-Skåne. Longer in time, more extensive collaboration with the city and } \\
\text { more police on site). } \\
\text { - Follow-up Tweets—-follow up on crimes, mostly about detaining criminals or } \\
\text { questioning (e.g., It's extremely tragic for a police officer to shoot someone, } \\
\text { https://t.co/p9Ue2AULM0 via @svtnyheter). } \\
\text { - Organizational Tweets—are Tweets that talk about the structure of police } \\
\text { work, colleagues, meetings with other police, etc. (e.g., Lpo Helsingborg today } \\
\text { welcomes I5 new police officers. Congratulations on graduating! Have a } \\
\text { fantastically exciting carrier, https://t.co/2aYiRMpen0). } \\
\text { - Reply Tweets/reflections-A low priority keyword which tries to catch the } \\
\text { police's own thoughts about subjects (e.g., I think this would help us, https://t. } \\
\text { co/xXyAsV7CST) or a catch all for any replies made in Tweets which are not } \\
\text { caught by other keywords (e.g., We have now identified I } 9 \text { of these. } \\
\text { Interrogation, possible prosecution and possible access ban are now awaiting, } \\
\text { https://t.co/wmoLTNW2Uz). } \\
\text { - Police education/vocation-Tweets about police work in action and } \\
\text { assignments; K9-units or special forces (e.g., police dogs will ensure safety for } \\
\text { runners, Local newspaper in Helsingborg, https://t.co/RTIrWhP3Ds). } \\
\text { Promoting event-are Tweets written by actors outside the police force to } \\
\text { promote events like seminars that are relevant for police work (e.g., Tomorrow, } \\
\text { Tuesday, we will make a new visit to Lammhult with our mobile police station. } \\
\text { Meet us after lunch. The mobile police station is equipped as a small police } \\
\text { station and has the opportunity to, among other things, report, answer } \\
\text { questions and can also work with road safety issues, https://t.co/dbrfbqijQI). }\end{array}$ \\
\hline
\end{tabular}

